\title{
Abdominal Scanning Using Autologous Human Red Blood Cells Labeled with Tc-99m: Detection of a Horseshoe Kidney
}

\author{
SEIICHIRO MORITA, MASATOSHI ISHIBASHI, TAKANOBU HIRAYAMA, \\ TUTOMU KUMABE, JUNICHI KOMURA*, HIROMICHI YANO*, \\ AND HISASHI OHTAKE
}

\author{
Department of Radiology and *Department of Pediatric Surgery, Kurume University \\ School of Medicine, Kurume, 830 Japan
}

Received for Publication December 25, 1989

\begin{abstract}
Summary: A horseshoe kidney was incidentally diagnosed while performing an abdominal scan using autologous human red blood cells labeled with Tc-99m (Tc-99m RBC) on a patient with suspected gastrointestinal bleeding. This patient repeatedly tested positive on occult blood stool examinations. In the first scintigram, an increase in well-defined activity was found on the right side under the liver. This could have been caused either by bleeding of the gastric antrum or the duodenal bulb. A second abdominal scan with Tc-99m RBC revealed faint radionuclide accumulation in the shape of a horseshoe with symmetrical, well-defined activity. However, the well-defined activity decreased with time on both images, and on this basis a horseshoe kidney was diagnosed.
\end{abstract}

Key Words: horseshoe kidney - abdominal imaging - ${ }^{99 m} \mathrm{Tc}-\mathrm{RBC}-$ emergency - intestinal bleeding

\section{Introduction}

Abdominal scintigraphy using red blood cells labeled with Tc-99m (Tc-99m RBC) is commonly used and recommended as a noninvasive technique to determine gastrointestinal bleeding sites (McKusick et al. 1981). A horseshoe kidney, a congenital renal malformation, may be unexpectedly found while performing bone scintigraphy on a field in nuclear medicine (Bannet and Dworking, 1977). We unexpectebly detected a horseshoe kidney by abdominal scintigraphy using Tc-99m RBC while investigating a suspected case of gastrointestinal bleeding.

\section{Case Report}

A 5-year-old boy was admitted because of a gastric ulcer associated with bloody vomiting. An upper GI series and gastrofiberscopy realed gastroesophageal reflux (Grade IV) caused by an esophageal hiatus hernia and a gastric linear ulcer at the greater curvature. Althogh he had taken medication for peptic ulcers for approximately one month, occult bleeding in the feces continued. A second endoscopic technique was performed and gastric and duodenal hemorrhage were still not detected. For this reason, abdominal scintigraphy using Tc-99m RBC was employed to detect bleeding from another area of the digestive tract. The scintigraphic image at $20 \mathrm{~min}$ (Fig. 1a) demonstrated well-defined activity on the right side under the liver. Initially, the images were interpreted to be bleeding from the pyloric antrum or duodenal bulb. However, the accumulation decreased at $90 \mathrm{~min}$ in 

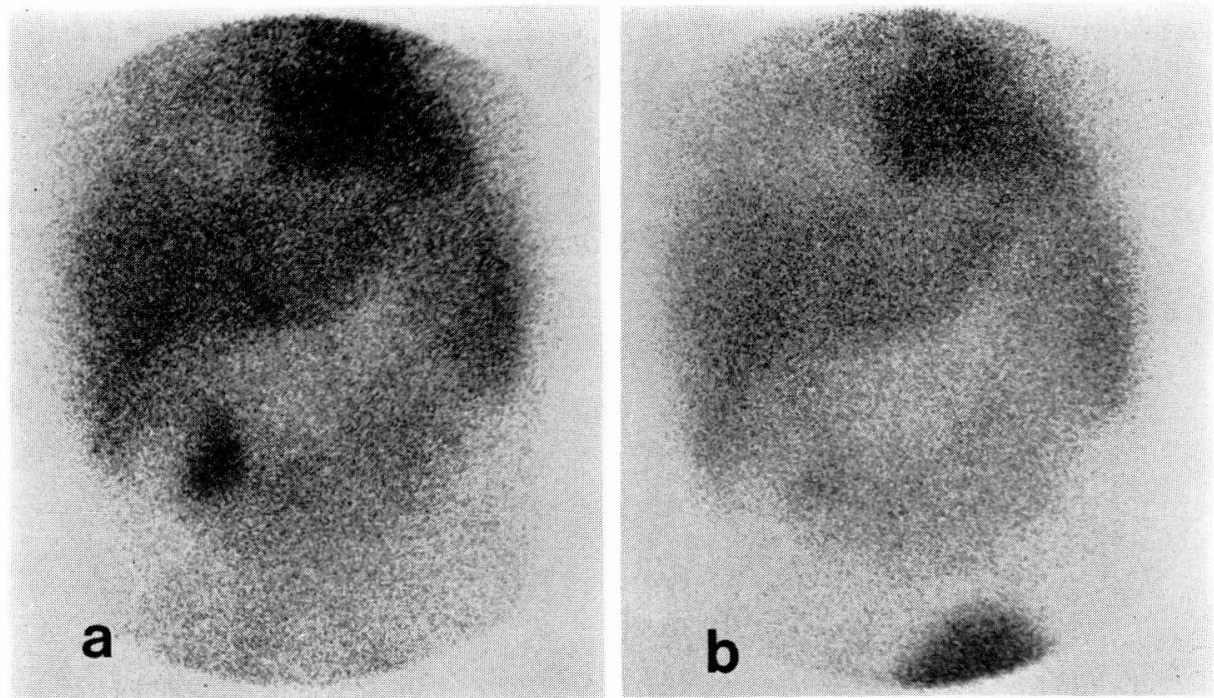

Fig. 1. a, An anterior Tc-99m RBC bleeding image at $20 \mathrm{~min}$. showing a well-defined activity in the right side under the liver. $b$, The well-defined activity was decreased at $90 \mathrm{~min}$.
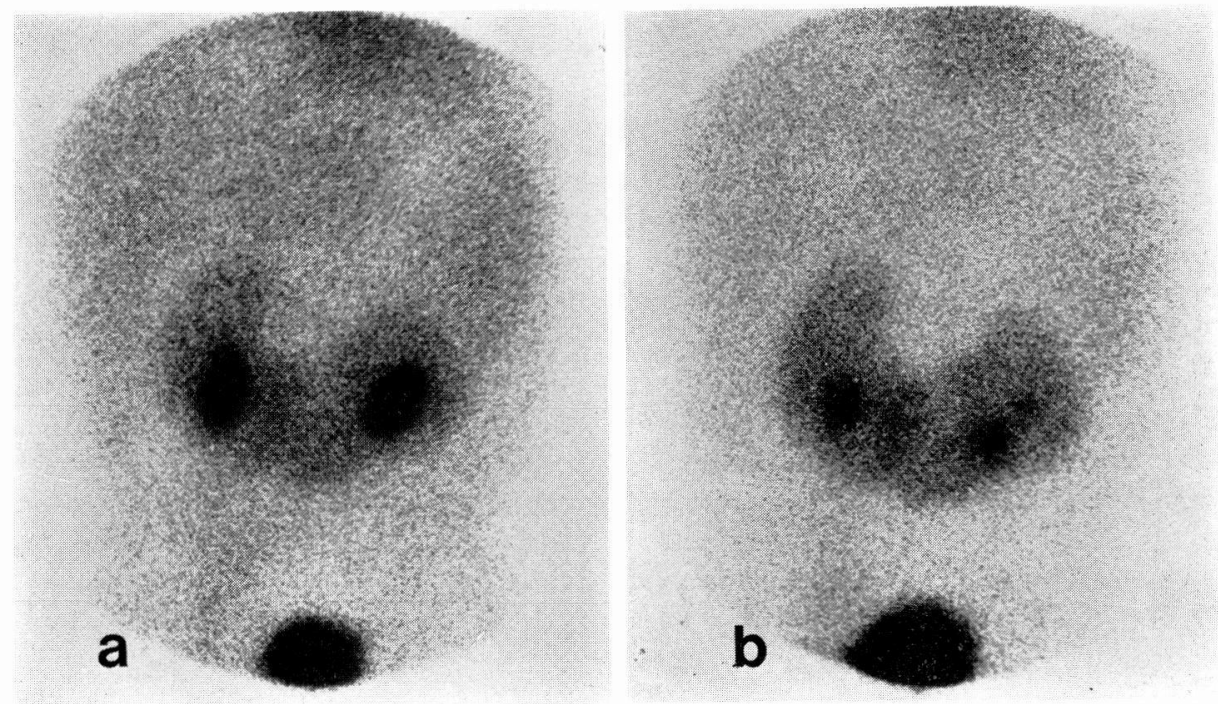

Fig. 2. a, A Tc-99m RBC image 3 weeks after the first examination. This anterior image, taken at $20 \mathrm{~min}$, showed a horseshoe-shaped area with symmetrical, well-defined activity. b, The activity again decreased at $90 \mathrm{~min}$. 
proportion to time implicating the kidney rather than gastroduodenal bleeding (Fig. 1b).

After three weeks radionuclide scintigraphy was again performed on this patient because of continued occult bleeding in the feces. The origin of the hemorrhage could not be determined. Fortunately, a striking image of a horseshoe kidney appeared, (Fig. 2a, b), which was subsequently confirmed by ultrasonography.

\section{Discussion}

The horseshoe kidney was coincidentally diagosed, while investigating other symptoms. Recently, new diagnostic imaging technologies are making this diagnosis easier. Among renal malformations, the frequency of horseshoe kidney is high. Campbell (1970) observed a frequency of 1:425 and Lowsley (1952) reported $1: 281$, using excretory pyelography. There are numerous reports on diagnosing horseshoe kidneys using Tc-99m MDP bone scintigraphy in the field of nuclear medicine (Bennet and Dworkin, 1977). The detection of a horseshoe kidney, while performing liver scintigraphy, has been previously descrived (Morita et al. 1984). Although abdominal scintigraphy was used twice, the results were not identical. There was no reasonable explanation for this difference due to the labolatory study, transfusion, or urine volume of the patient on the day when the scintigraphy was performed. Therefore, it is difficult to determine whether the differences of these images were caused by the patient or by the radiopharmaceuticals.

With respect to the pitfalls in the diagnosis of gastrointestinal bleeding using Tc-99m RBC, ectopic kidneys (Suzuki and Ootaki, 1984) and pelvic kidneys (Intenzo et al. 1984) have been reported. Datz and
Bilotta (1988) are the only other reseacher who have described the detection of a horseshoe kidney using scintigraphy with Tc-99m RBC. By observing the sequential alteration of radionuclide uptake during abdominal scintigraphy using Tc-99m $\mathrm{RBC}$, it may be possible to distinguish between gastrointestinal bleeding and an abnormal localization and morphology of the kidney.

\section{References}

Bennet, D. F. and Dworkin, H. (1977). Incidental detection of a horseshoe kidney on radionuclide bone image. Radiology 123, 392.

Cambell, M.F. (1970). Anomalies of kidney. In Urology, eds. Cambell, M.F. and Harrison, J.H., pp. 1447-1452. Philadelphia: W.B. Saunders Co.

Datz, F. L. and Bilotta, W.R. (1988). Horseshoe kidney simulating acute gastrointestinal hemorrhage on technetium-99m labeled red blood cell imaging. Clin. Nucl. Med. 13, 123-124.

Intenzo, C., Desai, A. and PARK, C. (1984). Falsepositive gastrointestinal bleeding study due to a pelvic kidney. Clin. Nucl. Med. 9, 523525.

Lecklitner, M. L. and Hughes, J. J. (1986). Pitfalls of gastrolintestinal bleeding stndies with ${ }^{99} \mathrm{~m}$ Tc-labeled RBCs. Semin. Nucl. Med. 16, 151-154.

LowsLey, O.S. (1952). Surgery of the horseshoe kidney. J. Urol. 67, 565-578.

McKusick, K. A., Froelich, J. W., Callahan, R. J., Winzelberg, G.G. and Strauss, H.W. (1981). Tc-99m red blood cells for detection of gastrointestinal bleeding. experience with 80 patients. Am. J. Roentgenol. 137, 1113-1118.

Morita, S., Nishi, F., Kajiwara, Y., Dannoura, R., Oshibuchi, M., Kikuchi, S., Оhtake, S. and Tакеока, A. (1984). A case report of horseshoe kidney incidentically detected by Tc-99mphytate liver scintigraphy. Jpn. J. Clin. Radiol. 29, 427-430.

Suzuki, Y. and Оотакі, M. (1984). Abdominal scanning with Tc-99m red blood cells false positive study due to ectopic kidney. Clin. Nucl. Med. 9, 616-618. 